\title{
Focusing (Pinched) Flow of Pure Electrons, Evidence against Einstein's Special Relativity
}

\author{
Panos T. Pappas ${ }^{1}$, Theocharis P. Pappas ${ }^{2} \&$ Eleftherios P. Pappas ${ }^{2}$ \\ ${ }^{1}$ Retired Professor, Athens, Greece \\ ${ }^{2}$ Department of Physics, University of Athens \\ Correspondance: Panos T. Pappas, 26 Markopoulioti Str., 11744, Athens, Greece. E-mail: ppappas@papimi.com
}

Received: July 28, 2014 Accepted: August 17, 2015 Online Published: August 21, 2015

doi:10.5539/apr.v7n5p66 URL: http://dx.doi.org/10.5539/apr.v7n5p66

\begin{abstract}
In this paper, in the following, we show that a flow (Filippova \& Filippov, 2015) of pure electrons can never self-focus, according to Special Relativity. Thus, it is contrary to everyday experience because such beams do focus (P. T. Pappas, L. P. Pappas, \& T. P. Pappas, 2014) in practice. Special Relativity is, thus, falsified.

However, the Non-Realistic Absolute Cardinal Ampere Force is compatible with everyday experience. For example in the welding arc, we use at homes.

The criterion is for which Theory; the Magnetic Attractive force overcomes the Coulomb Repulsive force of similar charges. This Magnetic force in S. Relativity never overcomes the Coulomb force.

The Magnetic force is not a monopoly of Special Relativity. It is a force between moving charges, thus of Ampere force. Therefore, this force concerns the Ampere Electrodynamics (Maxwell, 1891), because, the Ampere force is exclusively a force between moving charges. Thus, in this paper, we compare the Coulomb repulsion of moving similar charges, with that of S. Relativity Lorentz force; and with that of Ampere. The results are for Special Relativity; the Lorentz forces never surpass the Coulomb forces. Though, the Ampere forces do surpass the Coulomb forces in many occasions, giving many examples, as they do happen in practice.
\end{abstract}

Thus, S. Relativity is falsified. The Amper force and Ampere Electrodynamics has never been failed yet.

Keywords: Ampere Law, Coulomb forces, Lorentz forces, Magnetic field, Special Relativity

\section{Simple Short Proof for the Ampere Force (Maxwell, 1891) in Comparison with the Coulomb Force}

The Coulomb law force is (in S.I. units):

$$
\mathbf{F}_{12}=\left(1 / 4 \pi \varepsilon_{0}\right) \mathrm{q}_{1} \mathrm{q}_{2} \frac{\mathbf{r}_{12}}{\mathrm{r}_{12}{ }^{3}}
$$

with $k_{\mathrm{e}}=1 /\left(4 \pi \varepsilon_{0} \varepsilon\right),=1.602 \times 10^{-19} \mathrm{c}$.

The Ampere forces (P. T. Pappas, L. P. Pappas, \& T. P. Pappas, 2014) between moving ${ }^{7}$ charges with $\mathbf{V}_{\mathbf{1}}, \mathbf{V}_{\mathbf{2}}$ velocities, are: (in S.I. units):

$$
\mathbf{F}_{12}=\frac{\mu_{0}}{4 \pi} \frac{\mathbf{r}_{12}}{\mathbf{r}_{12}{ }^{3}} \mathrm{dq}_{1} \mathrm{dq}_{2}\left\{2 \mathbf{V}_{1} \cdot \mathbf{V}_{2}-\frac{3}{\mathrm{r}_{12}{ }^{2}} \mathbf{V}_{2} \cdot \mathbf{r}_{12} \mathbf{V}_{1} \cdot \mathbf{r}_{12}\right\}
$$

$\mu_{0} \varepsilon_{0}=1 / \mathrm{c}^{2}: \mu_{0}=1 / \varepsilon_{0} \mathrm{c}^{2}$. For side, by side moving with $\mathbf{v}$ of pure similar charges (Filippova \& Filippov, 2015; Pinch (plasma physics), 2015; Pinch effect in welding, 2015; Vladimirov, 1975), $\mathbf{r}_{12 . v}=0$, the Coulomb force minus the Ampere force is:

$$
\begin{aligned}
& \mathbf{F}_{12 C-A}=\left(1 / 4 \pi \varepsilon_{0}\right) d q 1 d q 2 \frac{r_{12}}{r_{12}{ }^{3}}-\left(\mathbf{1} / 4 \pi \varepsilon_{0}\right) \frac{r_{12}}{r_{12}{ }^{3}} d_{q} d_{q}\left\{2 V_{1} \cdot V_{2}-\frac{3}{r_{12}{ }^{2}} V_{2} . r_{12} V_{1} . r_{12}\right\}: \\
& \mathbf{F}_{12 C-A}=\frac{1}{4 \pi \varepsilon_{0}} \operatorname{dq}_{1} \mathrm{dq}_{2} \frac{\mathrm{r}_{12}}{\mathrm{r}_{12}}\left\{1-2 \mathrm{v}_{2} \cdot \mathrm{v}_{1} / \mathrm{c}^{2}\right\},
\end{aligned}
$$

It changes sign, when: $1-2 \mathrm{v}_{2} \cdot \mathrm{v}_{1} / \mathrm{c}^{2}=0$, for example: when $\mathrm{v}_{2}=\mathrm{v}_{1}=\mathrm{v}, 2 \mathrm{v}_{2} \cdot \mathrm{v}_{1}=\mathrm{c}^{2}$ :

$$
\mathrm{v}=\mathrm{c} / 1,41=212.765 \mathrm{Km} / \mathrm{s} \text {. }
$$


That is an example for this velocity; the Ampere force becomes bigger than the Coulomb force. Thus, the side by side pure electrons with $\mathrm{v}>212.765 \mathrm{Km} / \mathrm{s}$, or $\mathrm{v}_{2} \cdot \mathrm{v}_{1}=\mathrm{c}^{2} / 2$ do self-focus, according to the Ampere force.

However, in Relativity, the Magnetic force has limit the Coulomb force, for $\mathrm{v}=\mathrm{c}$, that is never reached. In such a case, we should not have self-focusing of moving of pure electrons (Filippova \& Filippov, 2015).

\section{Comparison of the S. R. Force and the Coulomb Force}

From the law of Biot-Savart $\mathrm{dB}$ is (in S.I units): (In parenthesis, We note, that $\mathrm{dB}$ was never possible to test, because there are no isolated sections of circuits, and thus, $\mathrm{dB}$ has never been proven correct. It is only hypothesized, supported only by a closed circuit integral, and when it is the same time $\mathrm{dB}$ is proven (P. T. Pappas, L. P. Pappas, \& T. P. Pappas, 2014) equivalent to the corresponding Ampere force. On the contrary, for non-closed circuits, dB violates (P. T. Pappas, L. P. Pappas, \& T. P. Pappas, 2014) momentum and angular momentum and it is proven non-equivalent to corresponding Ampere force that never violates momentum and angular momentum, retaining always action and reaction, as the Newton force law.):

$\mathrm{dB}=\mu_{0} / 4 \pi \mathrm{i} \mathrm{dl} \sin \theta / \mathrm{r}^{2}, \mathbf{k}=\mu_{0} / 4 \pi, \mu_{0} \varepsilon_{0}=1 / \mathrm{c}^{2}, \sin \theta=1, \mathrm{~dB}=\left(\mu_{0} / 4 \pi\right) \mathrm{dqv} / \mathrm{r}^{2}$, for $\mathrm{v}=\mathrm{c}, \mathrm{dB}=\left(\mu_{0} / 4 \pi\right) \mathrm{dqc} / \mathrm{r}^{2}, \mathrm{dE}=\left(1 / 4 \pi \varepsilon_{0}\right) \mathrm{dq} / \mathrm{r}^{2}$ $\mathrm{dB} / \mathrm{dE}=\mathrm{c} \mu_{0} \varepsilon_{0}=1 / \mathrm{c}$, then:

$$
\mathrm{dE}=\mathrm{c} \cdot \mathrm{dB}, \mathrm{d}^{2} \mathrm{~F}=\mathrm{dqdE}=\mathrm{dqcdB},
$$

Therefore, we should never have self-focusing with the S.R., as long $\mathrm{v}<\mathrm{c}$, that is always so. On the contrary (Filippova \& Filippov, 2015; Pinch (plasma physics), 2015; Pinch effect in welding, 2015; Vladimirov, 1975), see-Google "self-focusing electron beams", "pinch effect". Also, see "self-focusing beam vacuum radio tubes."

These all prove the non-Relativistic Cardinal Ampere forces and disprove the Special Theory Relativity.

\section{Conclusion}

In this paper, we have shown that a beam of pure electrons can never self-focus, according to Special Relativity. However, this is contrary to everyday experience, especially in the electronic beam vacuum radio tubes, because such beams do focus. Special Relativity is, thus, every day falsified in practice (Filippova \& Filippov, 2015; Pinch (plasma physics), 2015; Pinch effect in welding, 2015; Vladimirov, 1975).

On the contrary, pure electrons do self-focus, according to the Non-Relativistic Cardinal Ampere Force Law. The Ampere force has never been yet, found wrong in the history of humanity. According to the father of Electromagnetism, J. C. Maxwell, who wrote in his book: "this law should always remain the Cardinal Law of Electrodynamics."'(Maxwell, 1891)

Thus, the Ampere Electrodynamics, using the Cardinal Ampere Force (P. T. Pappas, L. P. Pappas, \& T. P. Pappas, 2014) is definitely superior to the Relativistic Lorentz Force Law, in theory and in every day practice.

\section{References}

Filippova, T. I., \& Filippov, N. V. (2015). Pinch Effect. In The free dictionary. Retrieved from http://encyclopedia2.thefreedictionary.com/Pinch+Effect

Maxwell, J. C. (1891). A treatise on electricity and magnetism. Clarendon press.

Pappas, P. T., Pappas, L. P., \& Pappas, T. P. (2014). Ampère cardinal forces-electrodynamics-Proof and prediction of empirical Faraday induction. Physics Essays, 27(4), 570-579.

Pinch (plasma physics). (2015). In Wikipedia, the free encyclopedia. Retrieved from https://en.wikipedia.org/wiki/ Pinch_(plasma_physics)

Pinch effect in welding. (2015). In Google Images. Retrieved from https://www.google.gr/search?q=Pinch+ effect + in + welding $\&$ tbm $=$ isch $\&$ tbo $=u \&$ source $=$ univ\&sa $=X \& v e d=0 C C c Q s A R q F Q o T C K K K s 9 u L I M c C F U K$ JLAodbykAgQ\&biw=1242\&bih=599

Vladimirov, V. V. (1975). The pinch effect in a solid-state plasma. Soviet Physics Uspekhi, 18(9), 690.

\section{Copyrights}

Copyright for this article is retained by the author(s), with first publication rights granted to the journal.

This is an open-access article distributed under the terms and conditions of the Creative Commons Attribution license (http://creativecommons.org/licenses/by/3.0/). 